Results After adjusting for age, smoking, alcohol use, BMI, physical exercise and chronic diseases, women engaged in shift work without night shifts in midlife had on average a $24 \%$ (due to shift work insomnia) and a $16 \%$ (due to shift work fatigue) higher risk for a unit increase in ML in old age than those without shiftwork insomnia and fatigue. Likewise, men engaged in shift work with night shifts in midlife had on average a $61 \%$ (insomnia) and a 66\% (fatigue) higher risk for a unit increase in ML in old age. Furthermore, women in shift work with night shifts and men in shift work without night shifts had on average a higher risk of ML, but the risk was attenuated and remained insignificant after adjustment.

Conclusions The findings of this prospective 28 year cohort study suggest that shift work related insomnia and fatigue in midlife have inverse effects on mobility functions in old age irrespective of gender and type of shift work, and indicates in the initiation of prevention of mobility decline in working life.

\section{EPIDEMIOLOGICAL STUDY BETWEEN TYPE 2 DIABETES AND BONE MINERAL DENSITY}

Kazuhiro Hidaka, Yoshiki Kuroda. Department of Public Health, Faculty of Medicine, University of Miyazaki

\subsection{6/oemed-2018-ICOHabstracts. 107}

Introduction In Japan, many people over 65 years old are working now. However, elderly working people frequently face to getting lifestyle diseases, so it would be important to control lifestyle diseases. Among lifestyle diseases, diabetes mellitus (DM) is a popular in the world. On the other hand, Osteoporosis is also an important disease for elderly workers, because osteoporosis is a risk to get fracture. There are some reports indicated that fractures was frequently in workers with DM. However, it was also reported that bone mineral density (BMD) in type $2 \mathrm{DM}$ patients was higher than non-diabetic persons. These reports were contradictory. Therefore, we planned to evaluate fracture risk and BMD of persons with type 2 DM comparing with healthy subjects.

Material and method We recruited 183 persons with type 2 DM (detail: 101 males, 82 females) under informed consent. We excluded persons with type 1 diabetes, rheumatic diseases. We collected individual data (age, sex, BMI, fasting blood sugar, average fasting blood sugar, $\mathrm{HbA1c}$ value, post history of fracture) and measure BMD using ultrasonic bone mass measurement.

Result

- BMD decreased with age. And BMD was higher than healthy subjects (Male and Female).

- In male, there was a significant positive correlation between MBD and BMI.

- In female, a significant positive correlation was found between BMD and fasting blood sugar.

- We didn't detect the difference concerning to fracture history between persons with DM and healthy persons.

Discussion We indicated BMD of DM persons was higher than healthy subjects. In addition, BMD of female was a significant positive correlation with the fasting blood sugar. But we could not indicate higher fracture risk in DM persons. We are planning to check whether fracture frequently happened or not in persons with DM.

\section{THE DETERIORATION TENDENCY OF HEALTH CONDITION IN AGE GROUP AND SEX BY FOLLOW-UP DATA}

${ }^{1} \mathrm{Y}$ Higuchi*, ${ }^{2} \mathrm{M}$ Ohta, ${ }^{3} \mathrm{M}$ Kumashiro. ${ }^{1}$ University of Teacher Education Fukuoka, Munakata, Japan; ${ }^{2}$ Fukuoka Women's University, Fukuoka, Japan; ${ }^{3}$ The Association for Preventive Medicine of Japan, Tokyo, Japan

\subsection{6/oemed-2018-ICOHabstracts. 108}

Introduction Along with the ageing society as a whole, the upper limit of the employment period in law has reached the age of 65 in Japan. It is thought that health risk increases in the elderly. In Japan, the age group subject to focused health promotion activities is considered to be in the $40 \mathrm{~s}$ and over. However, from the viewpoint of primary prevention, it is considered that measures to prevent disease are necessary before deterioration of health. Therefore, in order to obtain evidence on the deterioration of health condition, we have observed worker's health examination data over time.

Methods Health examination data for 14 years (2002-2015) were analysed. Within this period, the rate at which abnormal values appeared in blood pressure, GOT, total cholesterol, triglyceride, fasting blood glucose was calculated. The sample size is $n=25146$ who did not have missing values in all data. Results At the time of baseline (in 2002), abnormal values were found in the examined items, 55\% for males and 36\% for females. In 2015, they were 69\% (14\% increase) and $57 \%$ (21\% increase), respectively. By age group and gender, increase rate for male increased by $16 \%$ (38\% to $54 \%$ ) in their $20 \mathrm{~s}, 17 \%$ increase $(51 \%$ to $68 \%)$ in their $30 \mathrm{~s}, 9 \%$ increase in their $40 \mathrm{~s}(67 \%$ to $76 \%)$ and increased by $8 \%$ $(72 \%$ to $80 \%)$ in their $50 \mathrm{~s}$. For female, these rate increased by $4 \%$ (33\% to $37 \%)$, $19 \%$ (33\% to $52 \%), 32 \%(40 \%$ to $72 \%)$ and $11 \%(65 \%$ to $76 \%)$, respectively.

Conclusion With age, the appearance rate of abnormal values in major medical examination items increases. The tendency of the rate of increase varies depending on age group and. The rate of increase in male in their $20 \mathrm{~s}$ and $30 \mathrm{~s}$ is large, while in females the rate in their $40 \mathrm{~s}$ is large. From the viewpoint of disease prevention, it is necessary to develop health education to improve self-management ability and to review lifestyle habits from the stage before deterioration of health condition.

\section{OCCUPATIONAL SOCIAL CLASS AND SELF RATED HEALTH. A CROSS SECTIONAL STUDY OF OLDER IRISH ADULTS FROM THE IRISH LONGITUDINAL STUDY ON AGEING}

${ }^{1} \mathrm{~S}$ Kelly ${ }^{*},{ }^{2} \mathrm{~A}$ McCarren, ${ }^{3} \mathrm{~A}$ Reid. ${ }^{1}$ Specialist Registrar in Occupational Medicine, Tallaght Hospital, Dublin, Ireland; ${ }^{2}$ Dublin City University, Dublin, Ireland; ${ }^{3}$ Consultant Occupational Physician, Tallaght Hospital and Coombe Women and Infants University Hospital, Dublin, Ireland

\subsection{6/oemed-2018-ICOHabstracts.109}

Introduction Self-rated health has been shown to be an important predictor of future morbidity and mortality. We investigated the association between self-rated health and occupational social class in a population at work aged $\geq 50$ years in Ireland, and determined its relationship with demographic and health-related variables. 